\title{
Urolithiasis in a four-months-old Holstein colt
}

\author{
Eva-Christina Schliewert and Tim Steinberg \\ Tierklinik Lüsche, Bakum, Germany
}

\begin{abstract}
Summary: A four-months-old equine Holstein colt was presented with acute signs of respiratory disease. Following diagnostic evaluation, an initial diagnosis of pneumonia was made and treatment with broad-spectrum antimicrobials, intravenous fluid therapy, polymyxin B, clenbuterol, and dembrexine was initiated. The colt's condition deteriorated under therapy and repeat ultrasonographic evaluation revealed an accumulation of free fluid in the abdomen. On abdominoscentesis urine was obtained. Urethral endoscopy revealed hyperemic urethral mucosa and a hard, irregular, greyish structure $35 \mathrm{~cm}$ into the urethra. Surgery under general anesthesia was attempted and an area of necrotic tissue was found on the ventral aspect of the bladder. A spiculated oval stone was exteriorized but the defect could not be repaired as it was not accessible. The colt was euthanized. Urolith analysis revealed a composition of $90 \%$ tripelphosphate (struvite) and $8.2 \%$ apatite (rich in calcium). This case emphasizes the potential of obstructing urinary disease in very young animals. Knowledge of the potential presence of significant uroliths in suckling foals may help guide diagnostic evaluation and treatment and potentially allow for early intervention to prevent a fatal outcome.
\end{abstract}

Keywords: urolithiasis, equine, foal, urinary tract disease, acute abdomen

Citation: Schliewert E.-C., Steinberg T. (2019) Urolithiasis in a four-months-old Holstein colt. Pferdeheilkunde 35, 63-68; DOI 10.21836/PEM20190108

Correspondence: Dr. Schliewert, Faculty of Veterinary Science University of Pretoria Private Bag X04 Onderstepoort 0110. South Africa; tine. schliewert@web.de

\section{Case history}

A four-months-old equine Holstein colt was presented for further investigation of pyrexia. The barn manager reported that the foal was found to be more quiet than usual with a rectal temperature of $40.2^{\circ} \mathrm{C}$. The attending veterinarian recommended referral. The foal was born and housed in a breeding facility with a total of 35 mares and their foals. The horses were housed in group-stalls with daily turnout on pasture. The mares were fed a commercial concentrate and grass hay ad libitum as well as a mineral supplement. Reportedly, no other horses on the premises were affected.

On presentation in the afternoon, the colt had a depressed demeanor, with a heart rate of 72 beats per minute, respiratory rate of 36 breaths per minute and a rectal temperature of $39.9^{\circ} \mathrm{C}$. Mucous membranes were pink and tacky with a capillary refill time of 2-3 seconds. Jugular vein refill time was delayed. Respiratory effort was increased, with nostril flaring, and a mucous nasal discharge noted. Auscultation of the lung revealed harsh inspiratory sounds. Borborygmi were slightly decreased in all quadrants.

Blood was obtained for a complete blood count (CBC) and serum biochemistry analysis (Figure 1). Neutropenia with band neutrophils, monocytosis, and moderately increased SAA $(391 \mu \mathrm{g} / \mathrm{ml}$, reference $<15 \mu \mathrm{g} / \mathrm{ml})$ indicated an acute inflammatory response, increased hematocrit, serum protein, and creatinine were suggestive of hemoconcentration. Band neutrophils were noted. SAA was moderately increased to $391 \mu \mathrm{g} / \mathrm{ml}$ (reference $<15 \mu \mathrm{g} / \mathrm{ml}$ ).

Transcutaneous ultrasonographic examination (SonoSite Edge II, $6 \mathrm{MHz}$ linear probe) of the thorax revealed moderate comet tails over both lungs, no increased pleural fluid or abscesses were noted. No abnormalities were visualized upon transcutaneous ultrasound examination of the abdomen' (2 $\mathrm{MHz}$ convex probe).

Endoscopic examination of the upper airway was performed. Moderate pharyngeal follicular hyperplasia was observed. Grade 3 (Gerber et al. 2004) viscous yellow mucus was present inside the trachea; a sample was obtained transendoscopically in an aseptic manner for microbiological examination. The tracheal bifurcation was markedly thickened and hyperemic. Bronchospasm was observed during endoscopy. Arterial blood gas analysis was not performed.

A working diagnosis of pneumonia was made. A 14 G-over the wire catheter ${ }^{2}$ was inserted into the left jugular vein in an aseptic manner. Ceftiofur $(5 \mathrm{mg} / \mathrm{kg} \mathrm{IV} \mathrm{q} 12 \mathrm{~h})^{3}$ and meloxicam $(0.6 \mathrm{mg} /$ $\mathrm{kg} \mathrm{IV} \mathrm{q} 24 \mathrm{~h})^{4}$ therapy was initiated. Intravenous fluid therapy with 1 I equine plasma and Lactated Ringer solution (LRS) ${ }^{5}$ was started (5I bolus, then $1 \mathrm{l} / \mathrm{h}$ ). Polymyxin B (3000 IU/kg IV diluted in LRS q $12 \mathrm{~h}$, compounded) was added. Clenbuterol $(0.8 \mu \mathrm{g} / \mathrm{Kg}$ PO q $12 \mathrm{~h})$ and dembrexin $(0.6 \mathrm{mg} / \mathrm{kg} \mathrm{PO} \mathrm{q} 12 \mathrm{~h})^{6}$ were administered for bronchodilation and mucolysis respectively; sucralfate $(20 \mathrm{mg} / \mathrm{kg} \mathrm{PO} \text { q } 6 \mathrm{~h})^{7}$ for mucosal protection. Throughout the day the colt was quiet, alert and responsive, observed to suckle from the mare, to urinate and to pass soft feces. As the hydration status had not significantly improved in the evening (hematocrit $59 \%$ total protein $5.6 \mathrm{~g} / \mathrm{l}$ ), another fluid bolus (5I LRS) was administered. Over the following hours the foal started showing signs of discomfort. Heart rate increased to 108 beats per minute, and respiratory rate to 60 breaths per minute. Distention of the abdomen was noticed. Transcutaneous abdominal ultrasound was repeated and revealed a large volume of hypoechoic free peritoneal fluid containing multiple hyperechoic strands as well as floating loops of small intestine (Figure 1). The bladder could not be completely visualized; partially obscured by a hyperechoic structural abnormality in the dorsal bladder wall (Figure 2). 
Serum electrolytes were measured, all values were inside the reference ranges. Creatinine had decreased to $5.3 \mu \mathrm{mol} / \mathrm{l}$. Serum amyloid A had increased to $785 \mu \mathrm{g} / \mathrm{ml}$.

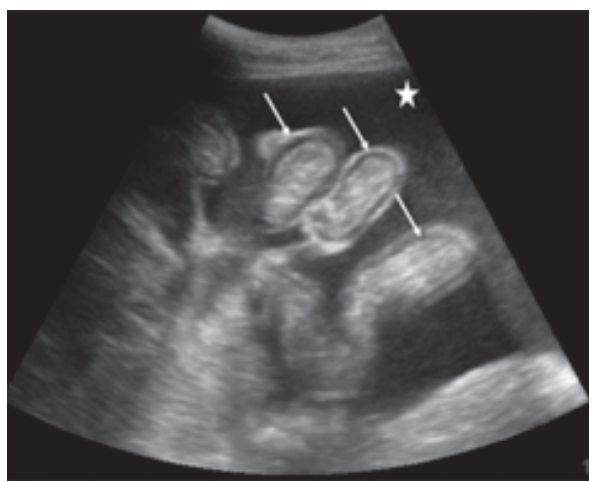

Fig. 1 Transcutaneous abdominal ultrasound image (obtained using a $2 \mathrm{MHz}$ frequency convex probea) showing increased volume of hypoechoic free peritoneal fluid with multiple hyperechoic strands (star) as well as floating loops of small intestine (arrows).

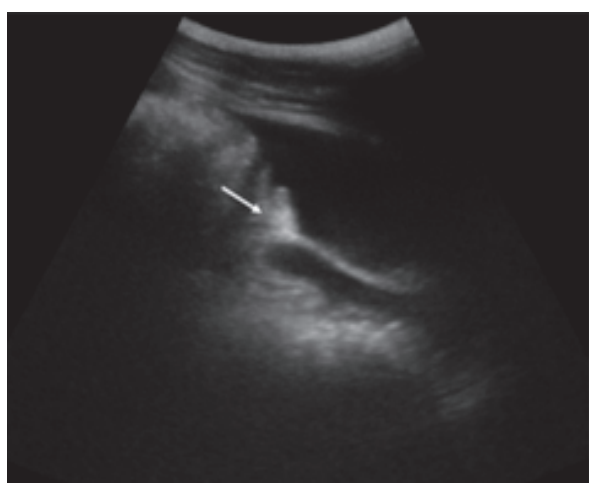

Fig. 2 Transcutaneous abdominal ultrasound image (obtained using a $2 \mathrm{MHz}$ frequency convex probea) showing a hyperechoic structural abnormality (arrow) in the dorsal bladder wall obscuring complete visualization of the bladder.

Abdominocentesis was performed, and yellow turbid fluid with a faint smell of ammonium was obtained. Fluid analysis revealed a creatinine of $12.8 \mu \mathrm{mol} / \mathrm{l}$.

Approximately 12 liters were drained from the abdomen, whilst the foal received a concurrent intravenous infusion of LRS.

Urethral urinary catheterization was repeatedly attempted under sedation (1 mg detomidine ${ }^{8}$ IV, $10 \mathrm{mg}$ acepromazine ${ }^{9}$ IV) but the catheter could not be passed further than $35 \mathrm{~cm}$ into the urethra from the urethral opening on the glans. Endoscopic examination into the urethra, revealed hyperemic urethral mucosa and a hard, irregular, brownish structure was visualized $35 \mathrm{~cm}$ into the urethra.

Treatment options were discussed with the owner and consent for a surgical therapy attempt was obtained. Surgery was performed under general anesthesia with the colt positioned in dorsal recumbency. The foal was premedicated with xylazine $^{10}(0.2 \mathrm{mg} / \mathrm{kg} \mathrm{IV})$, anesthesia induced with diazepam ${ }^{11}$ $(0.08 \mathrm{mg} / \mathrm{kg} \mathrm{IV})$ and ketamine ${ }^{12}(2.2 \mathrm{mg} / \mathrm{kg} \mathrm{IV})$. Anesthesia was maintained with inhalation of isoflurane ${ }^{13}$ in $100 \%$ oxygen via a cuffed endo-tracheal tube. The ventral midline skin was shaved and aseptically prepared. An approximately $15 \mathrm{~cm}$ longitudinal incision was made through the ventral midline starting $1 \mathrm{~cm}$ cranial to the umbilicus. Copious amounts of clear yellow fluid drained from the abdomen. On manual exploration of the abdomen the bladder was palpated and could be partially visualized but not exteriorized or manipulated into the incision. The serosal surface of the bladder was reddened and hyperemic. A wall defect could not be visualized on the ventral aspect of the bladder; the dorsal aspect could not be inspected entirely. A wall defect could not be detected by palpation.

Urinary catheterization was again attempted; the catheter could be advanced $35 \mathrm{~cm}$ into the urethra. The catheter tip within the urethra was palpated through the skin in the perineal region, and a hard structure was palpated next to it in the perianal region caudal to the scrotum. An incision was made over the catheter tip through the skin and into the urethra

Tab.1 Complete blood count and biochemistry findings at time of admission

\begin{tabular}{|c|c|c|c|}
\hline Parameter & Result & Reference Range & Unit \\
\hline Erythrozyten & 17.07 & $6.4-10.4$ & $T / \mathrm{I}$ \\
\hline Hämatokrit & 64.1 & $30-47$ & l/I (\%) \\
\hline Hämoglobin & 20.6 & $10.7-16.5$ & $\mathrm{mmol} / \mathrm{l}$ \\
\hline MCV & 37.6 & $41.1-52.4$ & $\mathrm{fl}$ \\
\hline $\mathrm{MCH}$ & 12.1 & $14.1-18.6$ & fmol \\
\hline $\mathrm{MCHC}$ & 32.1 & $32.8-38.6$ & $\mathrm{mmol} / \mathrm{l}$ \\
\hline RDWc & 43.6 & $24.6-33.3$ & $\%$ \\
\hline WBC & 5.18 & $4.9-11.1$ & $G / I$ \\
\hline Neutrophile & 38.3 & & $\%$ \\
\hline Lymphozyten & 35.1 & & $\%$ \\
\hline Monozyten & 26.6 & & $\%$ \\
\hline Eosinophile & 0 & & $\%$ \\
\hline Basophile & 0 & & $\%$ \\
\hline Neutrophile & 1.98 & $2.5-6.9$ & $M / I$ \\
\hline Lymphozyten & 1.82 & $1.5-5.1$ & $M / I$ \\
\hline Monozyten & 1.38 & $0.2-0.6$ & $M / I$ \\
\hline Eosinophile & 0 & -0.8 & $M / I$ \\
\hline Basophile & 0 & -0.1 & $M / I$ \\
\hline Thrombozyten & 202 & -250 & $\mathrm{G} / \mathrm{I}$ \\
\hline BUN & 42 & $6-27$ & $\mathrm{mmol} / \mathrm{l}$ \\
\hline CREA & 0.07 & $0.01-0.019$ & $\mathrm{mg} / \mathrm{dl}$ \\
\hline BUN/CREA & 7 & & \\
\hline $\mathrm{Ca}+$ & 10.5 & $9.4-11.8$ & $\mathrm{mmol} / \mathrm{l}$ \\
\hline TBIL & 2.9 & -4.1 & $\mu \mathrm{mol} / \mathrm{l}$ \\
\hline AST & 450 & -228 & nkat/l \\
\hline ALKP & 403 & -4667 & nkat/l \\
\hline GGT & 38 & -71 & $\mathrm{U} / \mathrm{I}$ \\
\hline GLU & 118 & -268 & $\mathrm{mg} / \mathrm{dl}$ \\
\hline CK & 662 & -473 & $\mu$ kat/l \\
\hline $\mathrm{LDH}$ & 1283 & -1830 & nkat/l \\
\hline TP & 7.7 & $4.7-7.2$ & $g / l$ \\
\hline ALB & 3 & -4 & $g / l$ \\
\hline GLOB & 4.7 & $1.8-3.6$ & $g / l$ \\
\hline
\end{tabular}


and a spiculated oval stone was exteriorized. The catheter was then advanced towards the bladder and exited into the abdomen at the neck of the bladder (transition bladder into urethra) through a lesion on the ventral aspect of the bladder.

The lesion could not be visualized through the incision; therefore, an inguinal approach was attempted. Another incision was made through aseptically prepped skin in the right inguinal region, but the defect could not be exteriorized, and the defect could not be repaired.

The foal was euthanized intraoperatively. Following euthanasia, a thorough examination of the bladder was performed. An area of approximately $3 \mathrm{~cm}$ diameter of necrotic tissue with a perforation of $1 \mathrm{~cm}$ was found in the most caudal part of the ventral bladder wall.

Culture results from the tracheal sample and the peritoneal sample were available the following day. Streptococcus equi ssp. zooepidemicus was identified from both locations.

The urolith was submitted for analysis. The stone was beige colored and had a size of $1.2 \times 2.9 \mathrm{~cm}$ with a rough surface. Analysis revealed a very unusual composition of $90 \%$ tripelphosphate (struvite) and $8.2 \%$ apatite (rich in calcium).

\section{Discussion}

In horses, uroliths are a rarely reported finding (Laverty et al. 1992, Diaz-Espiñeira et al. 1995). Uroliths are precipitated urinary crystals that form calculi. Formation is a multifactorial process. The most important prerequisite is high urinary concentration of soluble ionized minerals that aggregate and form insoluble crystals (Byers 2015). Contributing factors to precipitation and nucleation include supersaturated urine (Divers 2003), urine retention, certain genetic predispositions (increased excretion of certain substances), and imbalances of crystal growth inhibitors and promoters. Once precipitation exceeds dissolution, crystal growth occurs around a nidus (i.e. epithelial cells, foreign material etc.). Dissolution is also influenced by urinary $\mathrm{pH}$ and temperature. Calcium oxalate, purines, and cystine uroliths form typically in urine with a $\mathrm{pH}$ less than 7.0, whereas struvite calculi form typically in urine with a $\mathrm{pH}$ greater than 7.0 (Langston et al. 2008). Diet has been shown to influence urinary $\mathrm{pH}$ (Wood et al. 1990). With prolonged urinary retention or incomplete bladder emptying, the chance for crystal growth increases. Normal urine contains several crystal growth inhibitors such as pyrophosphate, citrate, magnesium ions, glycosaminoglycans, and different glycoproteins (Senior and Finlayson 1986, Smith 1989). Knowledge on inhibitor activity in horses is limited, but it may be assumed that these inhibitors in addition to the high urinary mucus content prevent calculus formation in the horse. Horses excrete large amounts of $\mathrm{CaCO}_{3}$ crystals in their urine and equine urine $\mathrm{pH}$ is alkaline, so protective mechanisms against stone formation are important and seem to be effective given the low reported incidence of uroliths in horses. Genetic variations resulting in altered ion excretion are described in humans and dogs (Treacher 1964, DiBartola et al. 1991, Audran and Legrand 2000) but have not been described in horses.
Reportedly, no other foals on the farm showed any signs of urinary disease. Foals were usually stabled with their dams overnight and horses had access to pasture during the day. All mares were fed hay free choice and a commercial pelleted feed to which the foals had access. Since no other mares or foals were affected, a solely dietary cause is therefore deemed unlikely.

Increased calcium intake and excretion has also been associated with increased risk for urolith formation (Remillard et al. 1992) but serum total calcium, magnesium and phosphate in this foal were within reference ranges, making chronic hyperexcretion an unlikely cause.

Uroliths are more common in older horses, previous publications report average ages of 8-10 years (Diaz-Espiñeira et al. 1995) and 10.5 years (Laverty et al. 1992). To the authors' knowledge, the youngest horses previously reported with urolithiasis were 18 months and 7 months old respectively, no further information on the clinical signs or the size of that stone in these specific patients was reported.

Foal urine is normally very dilute as foals are on a milk diet, decreasing the likelihood of crystal precipitation. With increased intake of solid feed, urine specific gravity increases (Edwards et al. 1990). Foal urine has also found to contain more calcium carbonate crystals than adult urine (Edwards et al. 1990), which is attributed to foal urine being more acidic. As the urolith in this foal was found to be struvite, calcium carbonate was not the main mineral component and likely acidic urine not the underlying cause. Unfortunately, urine was not obtained, so urine analysis was not performed. Given the size of the urolith and the necrotic condition of the tissue, a chronic pathology seems likely. Struvite stones are considered rare in horses (Edwards and Archer 2011, Diaz-Espiñeira 1995), $90 \%$ of stones are composed of calcium carbonate. Calcium is abundant in equine urine and aforementioned inhibitors of crystal growth, such as the high mucus content, are thought to play an important role in the prevention of urolith formation. In dogs, cats and humans, struvite stones are common. They are composed of magnesium ammonium phosphate hexahydrate $\left.\mathrm{Mg}^{2+} \mathrm{NH}_{4}+\mathrm{PO}_{4}{ }^{3-} * 6 \mathrm{H}_{2} \mathrm{O}\right)$. Uroliths occur when urine is oversaturated with magnesium, ammonium and phosphate. Stone formation can be classified as either infectious or sterile. The infectious form is as a consequence of urinary tract infection with urease-producing microbes such as Staphylococcus spp, Enterococcus spp, and Proteus spp and common in dogs. Sterile struvite is more common in cats with dietary composition as well as innate factors considered to be predispositions for urolith formation. Diets high in magnesium, ammonium and phosphate may increase the risk for stone formation by mechanisms of urinary excretion, but this does not seem a likely cause in this foal as it was on a milk diet with moderate intake of a balanced commercial concentrate (mare's feed). Innate factors such as an imbalance in crystallization inhibitors or a metabolic abnormality such as altered renal electrolyte excretion predispose for stone formation. In humans, hypercalciuria, hyperoxaluria, hypocitraturia, cystinuria, and hyperuricosuria have been described as major sources (Copelovitch 2012). Similar abnormalities were described in dogs (Treacher 1964) and cats (DiBartola et al. 1991) but not in horses. 
With sterile formation of struvite being unlikely in this case, a primary insult such as a subclinical or unnoted urinary tract infection is probable. Injury to the epithelium or bacteria may have functioned as a nidus, allowing for urolith formation. Suture material has been reported as a potential nidus (Schumacher and Schumacher 1999) but no previous surgery had been performed in this foal. Bacteria have long been recognized to contribute to struvite urinary stones in humans, dogs and cats (Syme 2010, Flannigan et al. 2014, Schwaderer and Wolfe 2017). Uroliths have been reported to be more common in females. This is due to the higher potential for developing an ascending infection, as females have a shorter and wider urethra which is also well recognized in other species (Osborne et al. 1995, Ling et al. 1998, Weichselbaum et al. 1998, Seaman and Bartges 2012). There is only limited information on the time it takes for a urolith to form de novo. Dogs have been shown to develop struvite uroliths in their lower urinary tracts within 2 weeks of the induction of staphylococcal urinary tract infection (Klausner et al. 1980). Considering the different factors involved, formation time may vary depending on urinary electrolyte saturations, urinary $\mathrm{pH}$, urinary concentration and micturition.

Streptococcus equi ssp. zooepidemicus was sampled from the peritoneal fluid and the tracheal aspirate, but its significance for the urinary pathology is questionable. Given the acute respiratory signs and the positive tracheal sample, it is likely that an unrelated Streptococcus equi ssp. zooepidemicus respiratory infection occurred and that it was not the causative agent for the urinary pathology. Streptococcal bacteria may then have spread to the abdomen hematogenously or have translocated into the abdomen to be cultured from the peritoneal fluid.

On admission, acute respiratory signs were present, prompting respiratory tract evaluation and initiation of therapy. With intravenous fluid therapy diuresis was promoted and urination observed. Overnight signs of urinary tract compromise became apparent. First straining with stranguria was noted, this progressed to a distended abdomen and increased respiratory effort. Repeated ultrasonographic evaluation revealed severely increased volumes of peritoneal fluid and prompted urinary tract evaluation. Given the extensive area of necrotic tissue in a location not accessible intraoperatively, it is unlikely that earlier surgical intervention could have changed the outcome. The damage was likely due to pressure necrosis over a prolonged period of time. Unfortunately, a histopathologic examination was declined by the owner.

Had urinary pathology been suspected in earlier stages of the disease, measures to either prevent calculus formation might have been implemented successfully. Promotion of diuresis is commonly advocated to prevent supersaturation of the urine. This can be achieved by supplementing feedstuffs with salt to increase water intake. 50-70 g of salt per day have been recommended for adult horses (Edwards and Archer 2011), quantities would have to be adjusted for foals. Given the dilute character of normal foal urine, this does not seem to be a valid treatment option.

As struvite stones are formed at $\mathrm{pH}>7$, acidification of the urine can be attempted. Urine $\mathrm{pH}$ of $<6$ has been achieved by supplementing ammonium chloride (20 to $40 \mathrm{mg} / \mathrm{kg} /$ day up to 60 to $520 \mathrm{mg} / \mathrm{kg} /$ day orally), ammonium sulphate (175 mg/ $\mathrm{kg} /$ day orally), methionine ( $1 \mathrm{~g} / \mathrm{kg} /$ day orally), or ascorbic acid (1 to $2 \mathrm{~g} / \mathrm{kg} /$ day orally) (Edwards and Archer 2011 ), however, results are inconsistent and these substances may be unpalatable at high doses.

Diets should be adapted to avoid high concentrations of magnesium, ammonium and phosphate. In horses, feeding alfalfa hay and calcium supplements should be discouraged, patients should be fed grass or oat hay instead. With suspected bacterial urinary tract infection, urine cultures should be acquired, and appropriate antimicrobial therapy initiated based on sensitivity results. If possible, antimicrobials that are excreted at high concentrations in the urine, such as penicillin or trimethoprim sulfa, should be preferred.

At later stages, either destruction or removal of the stone could have been attempted.

Urinary tract infection might have been suspected, had the managers noted any abnormalities in urination, such as stranguria, pollakisuria, or hematuria. Urinalysis in early disease might have supported infection, common findings are increased leukocytes (>10 per high power field) and erythrocytes in the urine. Quantitative culture with more than 10,000 colony-forming units is supportive of urinary tract infection (Schott 2015). Treatment with appropriate antimicrobials could then have been initiated.

If urolithiasis had been suspected, transabdominal ultrasound of the bladder and cystoscopy could have been performed at an earlier stage. Once uroliths have been diagnosed, there are several options to address the bladder stones. In mares uroliths can often be removed by hand following careful manual widening of the urethra. In male horses, a surgical approach by ventral celiotomy is commonly necessary to remove stones from the bladder. Electrohydraulic lithotripsy (Eustace et al. 1988, Roecken et al. 2012) and extracorporal shock-wave lithotripsy (Verwilghen et al. 2008) have also been used successfully in horses. In endoscopic electrohydraulic lithotripsy, shockwaves are generated next to the calculus, which is then fragmented. In contrast, with extracorporeal shock-wave lithotripsy, the shock waves are generated outside of the body and directed at the urethra, also resulting in fragmentation of the calculus. The fragments can then either pass through the urethra or be retrieved endoscopically. Early recognition of the urolith might have resulted in successful treatment of the urinary tract pathology.

Despite the outcome of this case, it emphasizes the potential of obstructing urinary disease in very young animals. In future cases, knowledge of the potential presence of significant uroliths in suckling foals may help guide diagnostic evaluation and treatment and potentially allow for early intervention to prevent a fatal outcome.

\section{Manufacturer's addresses}

1 SonoSite Edge II, FujiFilm SonoSite BV, The Netherlands

2 Arrow, Teleflex, USA

3 Excenel, Zoetis, Germany 
4 Metacam, Boehringer-Ingelheim, Germany

5 Ringer-Lactat-Lösung, Fresenius, Germany

6 Ventipulmin plus, Boehringer-Ingelheim, Germany

7 Sucrabest, Combustin, Germany

8 Domosedan, Vetoquinol, Germany

9 Calmivet, Vetoquinol, Germany

10 Xylazin 2\%, Serumwerk Bernburg, Germany

11 Diazepam, CP-Pharma, Germany

12 Ketamin, Medistar, Germany

13 Isoflo, Zoetis, Germany

\section{Conflict of interest statement}

The authors declare no conflict of interest.

\section{Acknowledgements}

The authors would like to thank Dr Lisanne Damhuis for assistance with this case.

\section{Literatur}

Audran M., Legrand E. (2000) Hypercalciuria. Joint Bone Spine 67, 509-15

Byers S. R. (2015) Urolithiasis. In: Large animal internal medicine. 5th edn. Ed: BP Smith Elsevier, St. Louis. 897-901

Copelovitch L. (2012) Urolithiasis in children: medical approach. Pediatr. Clin. North Am. 59, 881-96; DOI 10.1016/i.pcl.2012.05.009

Diaz-Espiñeira M., Escolar E., Bellanato J., Medina J. A. (1995) Structure and composition of equine uroliths. J. Equine Vet. Sci. 15, 27-34

DiBartola S. P., Chew D. J., Horton M. L. (1991) Cystinuria in a cat. J. Am. Vet. Med. Assoc. 198, 102-104

Divers T. J. (2003) Urine production, renal function, and drug monitoring in the equine intensive-care unit. Clin. Tech. Equine Pract. 2, 188

Edwards D. J., Brownlow M. A., Hutchins D. R. (1990) Indices of renal function: values in eight normal foals from birth to 56 days. Aust. Vet. J. $67,251-254$

Edwards B. and Archer D. (2011) Diagnosis and treatment of urolithiasis in horses. In Pract. 33, 2-10

Eustace R. A., Hunt J. M., Brearley M. J. (1988) Electrohydraulic lithotripsy for the treatment of cystic calculus in two geldings. Equine Vet. J. 20, 221-223

Gerber V., Straub R., Marti E., Hauptman J., Herholz C., King M., Imhof A., Tahon L., Robinson N. E. (2004) Endoscopic scoring of mucus quantity and quality: observer and horse variance and relationship to inflammation, mucus viscoelasticity and volume. Equine Vet. J. 36, 576-582

Flannigan R., Choy W. H., Chew B., Lange D. (2014) Renal struvite stones - pathogenesis, microbiology, and management strategies. Nat. Rev. Urol. 11, 333-341; DOI 10.1038/nrurol.2014.99
Klausner J. S., Osborne C. A., O'Leary T. P., Muscoplat C. M., Griffith D. P. (1980) Experimental induction of struvite uroliths in miniature Schnauzer and beagle dogs. Invest. Urol. 18, 127-132

Langston C., Gisselman K., Palma D., McCue J. (2008) Diagnosis of urolithiasis. Compend. Contin. Educ. Vet. 30, 447-450, 452-454

Laverty S., Pasoce J. R., Ling G. V., Lavoie J. P., Ruby A. L. (1992) Urolithiasis in 68 horses. Vet. Surg. 21, 56-62

Ling G. V., Franti C. E., Ruby A. L., Johnson D. L., Thurmond M. (1998) Urolithiasis in dogs. I. Mineral prevalence and interrelations of mineral composition, age, and sex. Am. J. Vet. Res. 59, 624-629

Osborne C. A., Lulich J. P., Bartges J. W., Unger L. K., Thumchai R., Koehler L. A., Bird K. A., Felice L. J. (1995) Canine and feline urolithiasis: relationship of etiopathogenesis to treatment and prevention. In: Canine and Feline Nephrology and Urology. Ed: Osborne C. A., Finco D. R. Williams \& Wilkins, Baltimore (MD). 798-888

Remillard R. L., Modransky P. D., Welker F. H., Thatcher C. D. (1992) Dietary management of cystic calculi in a horse. J. Equine Vet. Sci. 12, 359-363

Roecken M., Fuerst A., Kummer M., Mosel G., Tschanz T., Lischer C. J. (2012) Endoscopic-Assisted Electrohydraulic Shockwave Lithotripsy in Standing Sedated Horses. Vet. Surg. 41, 620-624; DOI 10.1111/i.1532-950X.2012.00977.x

Schott H. C. (2015) Urinary Tract Infection and Bladder Displacement. In: Robinson's Current Therapy in Equine Medicine. Ed: Sprayberry K. A., Robinson N. E. Elsevier (MO). 448-450

Schumacher J., Schumacher J. (1999) Surgical management of urolithiasis in the equine male. In: Large animal urogenital surgery. 2nd edn. Ed: Wolfe D. F., Moll H. D. Williams \& Wilkins, Baltimore (MD). 69-73

Schwaderer A. L., Wolfe A. J. (2017) The association between bacteria and urinary stones. Ann. Transl. Med. 5, 32

Seaman R., Bartges J. W. (2001) Canine struvite urolithiasis. Compend. Contin. Educ. Pract. Vet. 23, 407-420

Senior D. F., Finlayson B. (1986) Initiation and growth of uroliths. Vet. Clin. North Am. Small Anim. Pract. 16, 19-26

Smith L. H. (1989) The medical aspects of urolithiasis: an overview. J. Urol. 141, 707-10

Syme H. M. (2010) Stones in cats and dogs: What can be learnt from them? Arab. J. Urol. 10, 230-239; DOI 10.1016/i. aju.2012.06.006

Treacher R. J. (1964) The aetiology of canine cystinuria. Biochem J. 90, 494-498

Verwilghen D., Ponthier J., Van Galen G., Salciccia A., Sandersen C., Serteyn D., Grulke S. (2008) The use of radial extracorporeal shockwave therapy in the treatment of urethral urolithiasis in the horse: a preliminary study. J. Vet. Intern. Med. 22, 1449-1251; DOI 10.1111/ j. 1939-1676

Weichselbaum R. C., Feeney D. A., Jessen C. R., Osborne C. A., Koehler L., Ulrich L. (1998) Evaluation of the morphologic characteristics and prevalence of canine urocystoliths from a regional urolith center. Am. J. Vet. Res. 59, 379-387

Wood T., Weckman T. J., Henry P. A., Chang S. L., Blake J. W., Tobin T. (1990) Equine urine $\mathrm{pH}$ : normal population distributions and methods of acidification. Equine Vet. J. 22, 118-121 